\title{
Design of Virtual Simulation Teaching Platform for Mechanical Manufacturing
}

\author{
Zhe Wang ${ }^{1,}$ a * \\ Xi'an Aeronautical Polytechnic Institute. \\ No.500, Yingbin Avenue, Yanliang District, Xi 'an City, Shaanxi Province, China. \\ a604961630@qq.com \\ *The Corresponding author
}

Keyword: Mechanical; Virtual Simulation; Teaching Platform

\begin{abstract}
In view of little equipment, poor safety and bad quality for teaching, a virtual simulation teaching platform for mechanical manufacturing is proposed, which includes six modules, such as virtual machining simulation, installation and maintenance of equipment, integration of virtual reality of industrial robots, and integrated manufacturing of products. The platform can assist mechanical manufacturing practice teaching, greatly reduce the cost of teaching, reduce the potential danger in practice teaching, and improve the quality of teaching.
\end{abstract}

\section{Introduction}

Nowadays, more and more attentions are paid to the training of mechanical manufacturing professionals in higher vocational colleges. However, the disjointed teaching and production posts can't meet the urgent needs of the manufacturing application talents, due to the limited conditions of training and teaching[1]. The virtual simulation training teaching platform can avoid the constraints of the training field, equipment and funds, and realize the "zero distance" docking of the training teaching and the job to meet the needs of the enterprise for the excellent technical operator.

\section{The Problems in the Process of Traditional Training Teaching}

The Content of Practical Teaching is out of Date. The practical teaching materials of mechanical specialty in vocational colleges are very short. The existing books and materials have not been aimed at the actual production of enterprises, or the content is obsolete. There is a serious disconnection with the actual production of company. The productions have no practical value, and the technical requirements can't satisfy the enterprise products requirement.

The Practice Teaching Method is Single. The present vocational education has formed several comprehensive and systematic teaching modes, such as the working process-oriented model and the project teaching model. However, the implementation of these teaching methods is also restricted by many factors, such as the traditional teaching method of the mechanical manufacturing, which is usually the teacher giving students a drawing and several constraints, and then the students finish it by themselves, and there is not a standard of evaluation at the end of the training. Without paying much attention to it, many professional teachers in vocational colleges still lean towards the subject teaching mode, with single teaching methods and lack of professional practice skills.

The Facilities of Practical Teaching are Insufficient[2]. At present, the lack of capital investment in vocational education, especially the mechanical specialty needs a large amount of funds to add equipment for the training equipment. However, without the participation of the enterprise, the school is difficult to undertake the cost. Therefore, the vast majority of schools have the phenomenon of "fewer machines and more people", the students' professional skills are difficult to improve because of few training opportunities.

The "Double Teacher Type" Teacher Team is Lacking. Many vocational college teachers lack of practical experience in enterprise production, they don't understand the demand for business positions clearly. it may be the source that the theoretical knowledge can't cooperate with practical production. 
The Practice Training System is not Sound. Practice teaching has experiments, training and other teaching methods in the way of implementation, but the current vocational colleges and universities practice teaching base is not perfect, there is no sound practice system, assessment and evaluation mechanism[3].

\section{Design of Virtual Simulation Training Platform}

Taking manufacturing enterprises as simulation objects, the corresponding production processes are simulated on the virtual simulation teaching platform[4]. The platform is composed of virtual simulation module, mechanical equipment alignment and maintenance module, industrial robot virtual reality integration module, integration of reality and reality with advantages of high simulation, high situational, high immersion, high reference and interactivity[5]. Most of all, all the operators can finish the whole machining process of production, processing and manufacturing of typical products in the platform by themselves.

Virtual simulation module of machining. The virtual machine workshops are equipped with ordinary machine tools, CNC machine tools and three coordinate measuring instruments and other machining equipment. Besides, the workshop is consisted of preparation room, tool warehouse, process design room and quality inspection room, which can be fully used in the simulation teaching and training of various courses such as manufacturing technology, measurement and so on[6]. Students can understand the manufacture process of the parts from the drawing to the machining through analyzing the drawings, determining manufacture procedure, simulation cutting process to complete the whole parts manufacturing process, and experience the work of various job positions in the factory.

Equipment installation and service module. The tools and equipment required for mechanical assembly are provided in the workshop, which can be used for mechanical assembly and debugging of gear pumps, decelerator, ordinary lathes, CNC lathes and machining centers[7]. By assembling parts into machine tools, students can understand the dimensions matching, and grasp the knowledge of equipment install and service. After the mechanical assembly of the machine is completed, the construction and debugging of the circuit is needed to control the work of the motor and ensure the machine run smoothly. Otherwise, experiencers not only can enjoy cooperation with different professionals, but also expand their industry vision and enhance professionalism.

Theory, virtual and real integration module of industrial robot. Theory, virtual and real integration module of industrial robot is the combination of theoretical teaching, virtual simulation and real robot. This module can simulate a variety of robot operation and programming environment of mainstream robot manufacturers[8] After verifying the code of the robot control program generated by the virtual simulation software, it can directly output and drive the real industrial robot to realize the virtual simulation of the industrial robot to the practical operation and complete the real work task.

Manufacturing island with the integration of theoretical, virtual, reality. The virtual manufacturing island mainly includes digital design[9], virtual simulation processing, test, assembly and adjusting, which is based on the integrated product and relies on the team. By introducing the modern enterprise production process into the daily practice teaching, the production and management scene of the modern enterprise is simulated, and the integrated process and machining management of design, process and production are formed. Virtual production data and electronic data in the manufacturing island are transported to the required positions or equipment by team members with the aid of virtual transporting.

\section{The Application of Virtual Simulation Teaching}

Roaming function. The roaming function usually includes knowing the scene environment, knowing the facilities and equipment at the scene, and the basic requirements of safety production. The teaching effect of the realization of roaming function is to create a profound impression on the field environment, to solve the subject of professional cognitive practice, and to understand the field 
facilities and equipment initially, and to solve the problem of the post cognition practice. For example, the operator can visit any part of the workshop with the equipment and parts through the arrow keys to achieve the understanding of the production site and parts of the patch machine aiming to understand the internship software. At the same time, through linking, we can observe and learn other types of equipment.

Demonstration function. The demonstration function includes operation procedure demonstration, operation mode demonstration, contingency demonstration, error operation result demonstration and so on. For example, demonstration of wrong operation results has a strong simulative effect to inspire students' memories. The demonstration function can realize the following teaching effect: making the operator familiar with the operation process, making the operator understand the logical relationship of the operation process making the operator attach great importance to the safety operation and safety production and keeping in mind the serious consequences of the wrong operation. For example, by playing 3D demonstrative animation, the disassembly and decomposition process of the placement machine can be clearly displayed.

Interactive Function. Virtual simulation training for interactive function is the most important and most important kind of simulation training. The purpose is to let the students learn and master the prescribed operation skills according to some operating standard, so as to achieve the purpose of operation. The teaching contents of the interactive function include: using the multimedia means to vividly reproduce the content of the classroom teaching; use the operation of the mouse, keyboard or other physical equipment to carry out the ideal independent operation of the screen simulation object, realize the computer simulation teaching before the practical training, and the teaching content is consistent with the practical training. The teaching effect of the interactive function includes: through the full and vivid reproduction of the classroom teaching content, the students can deepen the understanding of the classroom teaching content and fully memory; through the reproduction of the "practical training points" in the teaching design, the teaching effect is realized. For example, the use of ordinary lathe simulation software, students can drag the parts through the mouse step by step to complete the operation of ordinary lathe disassembly.

Assessment Function. Simulation training examination can verify students' learning ability and display highlight core skills, which is inspiring, fair, inductive, interesting and directional. The main indexes of the evaluation system include whether the selected topic is random, the question bank is large enough, the examination content is corresponding to the core skills, the assessment means is scientific, reasonable and flexible, or realize the important role of the assessment function.

The Construction of Virtual Simulation Teaching Resources. The virtual simulation teaching resources construction takes teachers' self-development and production, cooperates with professional companies, and collects existing resources to carry on the construction of shared practical teaching resources in order to providing high quality interactive platform for learner autonomy, and sharing platform for similar specialties and enterprises in similar regional vocational schools. Virtual simulation teaching resources mainly include product case set, typical aviation manufacturing parts set, standard data and so on. The specific content of the case project is presented in the form of part drawing, assembly drawing, processing requirements, process list, numerical control program, part model diagram, tool list, part blank, simulation processing project, simulation processing video, quality inspection sheet, evaluation table, practical instruction and so on.

\section{Conclusion}

Compared with the traditional practice teaching methods, the established virtual training teaching platform has broken through the shortcoming of short training equipment, which has the advantages of low training cost, high security and extensive knowledge. Virtual simulation training platform can promote the improvement of teaching concept and improve students' interest in learning. As an effective supplement to the traditional practice teaching, virtual simulation teaching will be an important development direction of the practice teaching reform in the future, and it is of great significance for improving the quality of practice teaching and training. 


\section{References}

[1] B.J. Zhang. On the Teaching of Practical Training in Higher Vocational Education[J]. Career horizon, Vol. 6 (2010) No.3, p.61-62.

[2] M.J. Luo. Virtual Simulation Research of Automobile Repair in Secondary Vocational Schools[D]. Zhejiang University of Technology, (2011).

[3] X.H. Li. Professional Colleges and Universities Machinery Class Specialized Practice Teaching System Question and Countermeasure Research[D]. Hunan Normal University, (2013).

[4] T.X. Han. Reform of Mechanical Training Mode Based on Production Process [J]. Laboratory Research and Exploration, Vol. 33 (2014) No.10, p.229-233.

[5] J.N. Zhang, L.Z. Zhang. Research on the application of virtual simulation technology in experimental teaching [J]. Experimental Technology and Management, Vol. 30 (2013) No.12, p.101-104.

[6] W.L. Hu, H.Z. Jiao, B. Hu, M.L. Tao, Y.J. Hu, D.F. Chen. Research on Visualization of Intelligent Workshop In a Mechanical Equipment Enterprise Based on Virtual Reality Technology [J]. Journal of Nanchang Institute of Technology, Vol. 35 (2016) No.4, p.85-87.

[7] X.W. Yang. Research and Development of Servo System for CNC Machine Tool Maintenance Training Based on Vocational Education [J]. Mechanical \& Electrical Engineering Technology, (2018) No.4, p. 69-70.

[8] L. Ke, C.P. Zhou. Exploration and Practice of Talent Training Mode Based on "Dual System" in Germany [J]. Chinese Vocational and Technical Education, (2017) No.17, p.54-57.

[9] B. Shen, W. Chen. Application of Heuristic Simulation Optimization Technique on Design of Autonomous Manufacturing Island[J]. Chinese Journal of Mechanical Engineering, (2005) No.7, p. 71-79. 